\title{
Más que una condena: violencia contra mujeres por parejas y exparejas
}

More than just a conviction. Partner and ex-partner violence against women.

\author{
Cecilia Lorena Barraza Morelle \\ Universidad Santo Tomás, Bogotá, Colombia \\ ceciliabarraza@usantotomas.edu.co|http://orcid.org/0000-0002-3967-6281
}

\section{Adriana Benjumea Rúa}

Corporación Humanas, Colombia.

abenjumea@humanas.org.co|https://orcid.org/0000-0003-1665-3092

\begin{abstract}
Liliana Rocío Chaparro Moreno
Universidad Santo Tomás, Bogotá, Colombia.

lilianachaparro@usantotomas.edu.co|https://orcid.org/0000-0002-2063-0320
\end{abstract}

Recibido: 14 de agosto de 2020. Aprobado: 22 de septiembre de 2020.

DOI: $10.25100 /$ lamanzanadeladiscordia.v15i2.10505

Artículo de investigación

¿Cómo citar este artículo? / How to quote this article?

Barraza, Cecilia, Benjumea, Adriana, y Chaparro, Liliana. (2020). Más que una condena: violencia contra mujeres por parejas y exparejas. La Manzana de la Discordia, 15(2),1-29.

10.25100/lamanzanadeladiscordia.v15i2.10505 


\title{
Resumen
}

La violencia cometida contra las mujeres por parejas y exparejas es una problemática enfrentada en Colombia principalmente bajo la figura de la violencia intrafamiliar, que enfatiza en la afectación a la unidad familiar sobre las mujeres. En este artículo se analiza la respuesta estatal frente a esta forma de violencia a la luz de los debates sobre el lugar que la justicia debería tener para contribuir a enfrentarla y del derecho como instrumento de producción de sujetos y familias dignas de protección. Para el estudio seleccionamos de manera aleatoria 12 fallos en firme producidos entre 2018 y 2020 por juzgados de primera instancia de Bogotá sobre violencia contra las mujeres por parejas o exparejas. El estudio muestra que en casos excepcionales que llegan a sentencia condenatoria, el aparato judicial no toma en cuenta las estructuras de dominación y discriminación que explican dichas violencias y, en cambio, da un mensaje de protección a un modelo de familia heterosexual y de mujer cumplidora del mandato social, que excluye a otras familias y mujeres del amparo judicial. El poder simbólico del derecho no debe seguir siendo un sofisma en detrimento de una vida libre de violencias $y$ discriminación para las mujeres.

Palabras clave: Violencia, Mujeres, Parejas, Exparejas, Justicia, Violencia contra las mujeres.

\begin{abstract}
:
Violence committed against women by their partners or ex-partners is an issue faced in Colombia mainly under the domestic violence concept which emphasizes the affectation of the family unit over women's affectation. This article analyzes the state response to this form of violence in light of the debates on the role justice must play to contribute to coping with violence and the law as an instrument to produce subjects and families worthy of protection. For this study a random selection of 12 final judgments produced during 2018 and 2020 by first instance judges in Bogotá on violence against women by partners or ex-partners. The study shows that in exceptional cases with final conviction, the judicial apparatus does not take into account the domination and discrimination structures that explain said violence and, instead, provides a message towards the protection of a heterosexual family model with a woman that meets social mandates, excluding other types of families and women from their right to judicial protection. The symbolic power of law cannot continue to be a sophism to the detriment of a free of violence and discrimination life for women.
\end{abstract}


Key words: Violence,Women, Partner, Ex-partner, Justice, Violence against Women.

\section{Introducción}

El 7 de junio de 2017 la Corte Suprema de Justicia colombiana falló en el caso de una mujer que había sido agredida por quien entonces era su expareja y con quien convivía bajo el mismo techo. En dicho fallo la Corte señaló que el caso se configuraba como violencia intrafamiliar, dada la convivencia demostrada, y no por el hecho de haber tenido una relación afectiva de la cual resultaron hijos en común. Con esta decisión quedó de manifiesto que en Colombia el camino judicial más eficaz para proteger a las mujeres de la violencia cometida por parejas y exparejas era la violencia intrafamiliar, aún cuando los hechos sobrepasaran las características de la violencia de la familia. Además, hizo evidente un vacío normativo en materia de protección de mujeres víctimas que estuvieran fuera del amparo de la tipificación de violencia intrafamiliar: todas las exparejas con o sin hijos, que no vivieran bajo el mismo techo quedaban desprotegidas por esta vía.

En respuesta al vacío que hizo evidente la decisión de la Corte, la Fiscalía General de la Nación propuso un proyecto de ley que fue aprobado bajo la Ley 1959 de 2019. Dicha norma amplió el espectro de la violencia intrafamiliar a cualquier tipo de relación afectiva matrimonial o extramatrimonial, aunque hubiere finalizado y se hubiera procreado o no.

Tanto la decisión de la Corte Suprema de Justicia como la respuesta de la Fiscalía y del Congreso, evidencian un problema que urge ser debatido públicamente y que se expresa en la pregunta que motiva este artículo: ¿El tratamiento judicial que el Estado colombiano brinda a la violencia contra las mujeres cometida por parejas y exparejas contribuye a superar la discriminación y dominación que la genera o, por el contrario, las refuerza?

La relevancia de esta pregunta se asocia también a la gravedad de la problemática. En el marco de lo que establece la ley como violencia intrafamiliar cometida contra parejas y exparejas, las cifras en Colombia alarman por su magnitud y frecuencia. Las últimas cifras reportadas por el Instituto Nacional de Medicina Legal y Ciencias Forenses (INMLCF, 2019) corresponden a las 
del año 2018, año en que se reportaron 49.669 dictámenes por violencia de pareja, de los cuales 42.753 afectaron a mujeres, es decir, el $86 \%$ (p. 199). Del total de casos en los que fueron víctimas mujeres y cuyos hechos se conocen, los responsables de la violencia fueron: 56,53\% compañeros permanentes y $34,52 \%$ ex compañeros permanentes (p. 204).

No solo estamos ante una problemática masiva, marcada por motivaciones basadas en el género, sino que tratamos con un tipo de violencia potencialmente mortal. Así lo demuestran los datos del INMLCF que en materia del riesgo de feminicidio, entre 2014 y 2017 dijo que fueron valoradas 23.189 mujeres, de las cuales el 33\% estaban en riesgo extremo, el $28 \%$ en riesgo moderado, el $21 \%$ en riesgo grave y el $17 \%$ en riesgo variable. El Instituto también afirmó que "el riesgo grave ha ido en aumento a través de los años, así como el riesgo extremo, que en la mayoría de los casos tiene los mayores porcentajes" (INMLCF, 2017, p.22) ${ }^{1}$. En el año 2016, el INMLCF determinó que 3.414 mujeres se encontraban en riesgo grave o extremo de violencia feminicida y requerían protección del Estado para garantizar sus vidas; para octubre del año 2018 de estas mujeres 43 ya habían sido asesinadas (Guzmán Pardo, 2019).

Para responder a la pregunta planteada en este artículo proponemos cuatro partes, la primera se enfoca en las bases conceptuales que ponen en diálogo algunas teorías feministas con la problemática de la violencia contra las mujeres cometida por parejas y exparejas y que explican sus diferencias respecto de otras problemáticas como la violencia intrafamiliar. La segunda parte se concentra en los debates sobre la familia donde se presenta la respuesta estatal y normativa a la violencia estudiada. La tercera sección estudia doce (12) sentencias de violencia cometida contra mujeres por parte de sus parejas o exparejas, las cuales fueron proferidas en la ciudad de Bogotá entre los años 2018 y 2020. Por último, se presentan las conclusiones.

En Colombia existen estudios sobre la violencia intrafamiliar y la justicia que se ocupan principalmente de experiencias locales y de análisis jurisprudencial, aunque en muchas ocasiones

\footnotetext{
${ }^{1}$ El Protocolo de Valoración del Riesgo Feminicida es una herramienta predictiva que analiza los factores de riesgo dentro de una escala y el contexto dentro del cual se encuentra la víctima, el entorno dentro del que se presenta la dinámica violenta; y, por ende, la cultura a la cual pertenece la víctima. Está definido para aplicar a mujeres que viven violencia por pareja o expareja. Su objetivo, según el nivel de riesgo determinado, es recomendar a las autoridades medidas de protección y atención de la Ley 1257 de 2008 (Instituto Nacional de Medicina Legal y Ciencias Forenses, 2017).
} 
no diferencian la violencia intrafamiliar de la violencia cometida por parejas y exparejas ${ }^{2}$. Además de estos estudios, las reflexiones y avances de litigio estratégico en temas de violencias contra las mujeres y las niñas realizadas por organizaciones de mujeres en el país, que para el año 2008 dieron como resultado la Ley 1257 o en el marco de las movilizaciones por el feminicidio de Rosa Elvira Cely impulsaron el surgimiento de la de Ley 1761 de 2015, son fundamentales para seguir abriendo debates y contribuyendo desde el activismo, la academia, el derecho y la salud a fin de erradicar la impunidad en temas de justicia para las mujeres víctimas de violencia por parte de sus parejas o exparejas. Partiendo de los hallazgos de estos estudios y trabajos, este artículo resulta novedoso en tanto se propone el estudio de sentencias donde los agresores han sido condenados, lo cual permite abrir preguntas sobre el alcance de la justicia esperada desde un enfoque feminista que se pregunta por la apropiación del cuerpo de las mujeres, que simbólicamente autoriza a los varones a disponer de los mismos, incluso hasta su eliminación.

\section{Bases conceptuales desde las teorías feministas sobre la violencia contra las mujeres cometida por parejas y exparejas}

En el contexto general de la violencia contra las mujeres encontramosque la violencia cometida por parejas y exparejas constituye una problemática social que puede tener dinámicas diferentes a la violencia intrafamiliar o doméstica y a otros tipos de violencia contra las mujeres que no incorporan necesariamente un vínculo entre los afectados. Esto porque si bien la violencia intrafamiliar incluye cualquier acto de maltrato físico o psicológico en contra de cualquier integrante del núcleo familiar ${ }^{3}$, la mediación de relaciones de poder y de un contexto de histórica discriminación basado en la construcción de diferencias de género entre hombres y mujeres en el marco de un sistema heteropatriarcal, conlleva a una violencia de naturaleza diferente que

\footnotetext{
${ }^{2}$ Dentro de las publicaciones más recientes encontramos artículos y trabajos de grado que se ocupan de la cuestión desde los enfoques penal, familiar, procesal o administrativo (Castro y Jaramillo, 2018; Cubillos, 2020; Gómez y Estrada, 2017; Goyeneche et al., 2018; Indaburu y Sarmiento, 2020; Martínez y Rodríguez, 2020; Osorio y Pérez, 2018; Ramos-Aranda et al., 2018; Sarmiento y Pinzón, 2019). Un texto que trabaja la problemática específica de la violencia cometida por exparejas se encuentra en Forero (2018), además del texto que plantea el debate sobre el carácter familiar o no de la violencia cometida por exparejas y parejas (Chaparro, 2020).

${ }^{3}$ Parejas, padres o madres, ascendientes o descendientes o cualquier persona integrada de manera permanente a la unidad doméstica (art. 230 Código Penal). En ese sentido, la violencia entre parejas puede ser parte de la violencia intrafamiliar, pero no toda forma de violencia intrafamiliar es constitutiva de violencia por parejas o exparejas. En el mismo sentido ver Londoño et al. (2013, p. 6).
} 
demanda respuestas distintas por parte del Estado para garantizar la atención, protección y reparación de las víctimas ${ }^{4}$.

Aunque la violencia cometida por parejas y exparejas-conocida en inglés como IPVAW (intimate partner violence against women) - es una forma de violencia contra las mujeres, tiene unas particularidades que la distinguen de otras formas de violencia que se cometen en contra de las mujeres. La violencia que proviene de las parejas y exparejas supera el ámbito familiar porque puede darse sin que existan lazos familiares como ocurre, por ejemplo, en las relaciones que no involucran convivencia, en las de noviazgo, en las intermitentes y extramatrimoniales. Esta violencia es paradigmática del amor romántico y del consecuente deber impuesto a las mujeres de mantenerse en relaciones de pareja heterosexuales, a lo que se supedita su estatus social. La violencia por parejas y exparejas es independiente del ámbito en que se comete y puede darse en relaciones afectivas vigentes, finalizadas o en proceso de finalización, independientemente de que medie el afecto. Además, la relación de esta violencia con el feminicidio es estrecha, si se tiene en cuenta que un número significativo de asesinatos contra mujeres son cometidos por sus parejas o exparejas como una expresión más de la violencia.

Para profundizar en la violencia contra las mujeres como un problema social es relevante ampliar el espectro de análisis, no solo a lo normativo, sino tomar en cuenta los desarrollos conceptuales en esta materia provenientes de las ciencias sociales y en especial de las académicas feministas. Dos aspectos resultan relevantes: la consideración misma de la violencia en términos generales y la violencia específica contra las mujeres cometida por parejas y exparejas.

\footnotetext{
4 De acuerdo con San Juan Guillén y Vergara Iaeta, la violencia de pareja "Se enmarca en un contexto de desequilibrio de poder e implica un conjunto de acciones, conductas y actitudes que se mantienen como estilo relacional y de interacción imperante en la pareja donde normalmente un hombre, por acción u omisión, ocasiona daño físico y/o psicológico a una mujer" (citado en Londoño, 2013, p. 1). Esta violencia es incluida en la categoría más general sobre violencia contra la mujer que fue establecida, entre otros instrumentos internacionales, en la Declaración sobre la eliminación de la violencia contra la mujer (OACDH, 1993) que la definió como "todo acto de violencia basado en la pertenencia al sexo femenino que tenga o pueda tener como resultado un daño o sufrimiento físico, sexual o sicológico para la mujer, así como las amenazas de tales actos, la coacción o la privación arbitraria de la libertad, tanto si se producen en la vida pública como en la vida privada"(artículo 1). Un año después, la Convención Interamericana para Prevenir, Sancionar y Erradicar la Violencia contra la Mujer (CIM, OEA, 1994) la definió en un sentido similar.
} 
Siguiendo a Martínez(2016), se pueden establecer dos vertientes de análisis de la violencia en cualquier circunstancia: aquella que asocia la violencia con eluso de la fuerza para causar daño y otra que amplía el concepto de violencia a la negación del otro. En la primera vertiente, cobra relevancia la intención de causar daño de quien propicia la violencia y la existencia de un sujeto pasivo que la recibe; en esta corriente no se incorporan en la conceptualización los elementos del contexto y se vuelve complejo el análisis de la intencionalidad, el resultado y el fin de la violencia, restringiendo su estudio a un carácter instrumental definido como un medio para lograr un fin. Esta es una corriente limitada, pues deja por fuera formas de violencia que no se asocian a la fuerza y que se enfocan en la regulación de la vida de las mujeres desde diferentes planos; en otras palabras, desde esta interpretación general de la violencia no es posible acercarse a las relaciones de poder que están inmersas en la discriminación que subyace a la violencia contra las mujeres. En la segunda vertiente, el concepto se amplía al señalar la violencia como un acto relacional que niega la subjetividad del otro. La primera vertiente de conceptualización de la violencia puede ser muy útil para la aplicación de la normativa de la violencia contra las mujeres, puesto que al establecer al sujeto generador de la violencia permite su penalización, pero es limitada porque no considera los aspectos culturales y estructurales de dicha violencia (Martínez, 2016)lo que, en el caso de la violencia contra las mujeres, permite incorporar el concepto de continuum de las violencias.

Por tanto, es desde la segunda y más amplia vertiente que nos aproximaremos a la violencia contra las mujeres y en particular a la cometida contra mujeres por parejas y exparejas. Siguiendo esta línea, asumimos que la violencia usada para causar daño a las mujeres ocurre en un contexto configurado por dos elementos:un contexto social amplio definido por unas condiciones históricas de discriminación que afectan a todas las mujeres y que involucran la violencia simbólica (sistema patriarcal); y un contexto restringido al espacio en que se realizan dichos actos, es decir, en la materialidad de las relaciones concretas. Al reconocer el contexto como un elemento central en la violencia contra las mujeres, cobra sentido el continuum de las violencias desde una lógica espacio temporal y, por ende, una problemática estructural de la sociedad, en la cual las diferentes formas de violencias cometidas contra las mujeres están conectadas al responder a una forma de control social para mantener la dominación masculina hegemónica(Kelly, 2000). 
Los elementos anteriormente señalados nos remiten a la noción de violencia de género, que puede ser entendida como aquella ejercida en el marco de un contexto caracterizado por relaciones desiguales de poder, donde la jerarquía ha sido socialmente producida. Y en nuestras sociedades afecta principalmente a las mujeres y a los grupos con orientaciones sexuales o identidades de género no hegemónicas (Barraza, 2018). Esto implica considerar que la violencia está motivada por razones asociadas al género y, en el caso de la violencia de género hacia las mujeres, que es aquella que ocurre por el hecho de ser mujeres. Esto implica considerar la construcción social del ser mujeres y el mantenimiento de una estructura de subordinación, opresión y dominación basada en la discriminación(Isaza, 2006; Echeverry y Bernal, 2015; Viveros, 2016; Barraza, 2018; Poggi, 2019; Lux y Pérez, 2020).

A estas interpretaciones de la violencia contra las mujeres y en particular la cometida por parejas y exparejas como una manifestación del poder patriarcal, se oponen algunas críticas que señalan que el género es solo un componente más del análisis ya que existe una simetría en las relaciones de pareja. Estas aproximaciones, que podemos clasificar como teorías individualistas de la violencia, señalan que la violencia de pareja es producto de procesos causales más que de relaciones de poder desiguales; algunos autores plantean que la violencia es innata o natural en los hombres (Risman, 1998 citado en; Anderson, 2005). Estas teorías presentan algunos problemas. En primer lugar, reducen el análisis de género a un asunto del comportamiento de hombres y mujeres como sujetos individuales; esto quiere decir que si algunos hombres y algunas mujeres son violentos, la violencia no tendría género. En segundo lugar, no logran explicar por qué estadísticamente los hombres son más violentos que las mujeres. En tercer lugar, no explican qué diferencias biológicas habría entre los hombres que ejercen violencia y los que no y entre las mujeres que la practican y las que no, habiendo recibido un proceso de socialización similar. Por último, aluden a que la violencia también se presenta en relaciones homosexuales, pero no analizan justamente la socialización e identificación de roles y estereotipos (Anderson, 2005). Un importante aporte para contrarrestar las teorías individualistas fue el de MacKinnon (1995) al evidenciar que las mujeres víctimas no son víctimas de hombres individuales sino de un sistema patriarcal que enseña esa conducta para controlar y cuyo sistema no castiga significativamente esa violencia (Carroll, 2012). 
Tomando en cuenta los argumentos que preceden, conceptualmente nos enfocaremos en el hecho de que la violencia contra las mujeres no es natural, se trata de una conducta aprendida socialmente a lo largo de la historia que se da en la interacción social cotidiana, es decir, es un resultado de las prácticas sociales.De allí que la violencia no sea neutra desde el punto de vista del género, puesto que la masculinidad se construye a través de prácticas de violencia para reafirmarla o cuando esta masculinidad se encuentra amenazada (Anderson, 2005; Jelin, 2010, p. 170). Por tanto, la violencia contra las mujeres es estructural y cultural: estructural toda vez que sistemáticamente ocurre contra ellas resolviéndose a favor de los hombres dada la estratificación social existente; cultural ya que logra crear un marco legitimador de la violencia, es decir, es capaz de crear una estructura social(Galtung, 2003).Dado su carácter estructural y cultural, esta violencia ejercida contra las mujeres por parejas y exparejas es también simbólica, moral y homologable a la tortura. Sobre ello nos referiremos a continuación.

En tanto violencia simbólica,la violencia contra las mujeres construye diversos mensajes que logran transmitir y reproducir diferentes formas de discriminación buscando naturalizar o justificar dicha violencia y generando consecuencias en quien la recibe (Martínez, 2011). En este sentido, puede no ser física, pero sí tener consecuencias inmediatas y visibles(Lagarde, 2003, sec. cap. VII y IX). De hecho, los estudios sobre la violencia cometida por parejas incorporan el concepto de "ciclo de la violencia" para explicar su inicio sutil y con baja intensidad en una espiral de tensión, agresión y arrepentimiento que pueden generar en la víctima efectos adversos en su salud mental y en su capacidad de relacionamiento(Garzón, 2006; Walker, 2012). Esta espiral tiene un fuerte componente simbólico con capacidad de perpetuar la violencia en el tiempoy se configura en un problema de salud pública(Ellsberg et al., 2008).

También, la violencia contra parejas y exparejas puede expresarse como una violencia moral, según el desarrollo conceptual de Segato. Esta autora plantea que la violencia moral "es todo aquello que envuelve agresión emocional, aunque no sea ni consciente ni deliberada”, puede manifestarse únicamente a través de "gestos, actitudes o miradas" y es por ello considerada como un "instrumento de alienación de los derechos humanos de las mujeres" (Segato, 2003, p. 115).Esta violencia permite que las mujeres víctimas interioricen y acepten el sistema de 
dominación, señalándoles el lugar que ocupa la mujer en la sociedad y construyendo un sistema de pensamiento que permite su subordinación a dicho sistema (Martínez, 2016).En el marco de este sistema patriarcal,los agresores ejercen prácticas sexistas de subordinación sobre las mujeres, propios de sistemas heteronormativos, en el cual se involucran tanto estereotipos y actitudes negativas, como aparentemente positivas que las mantienen limitadas a ciertos roles(Expósito et al., 1998).

Por otra parte, como lo señala Falquet (2017), existen elementos en común que nos permiten afirmar que la violencia doméstica es una forma de tortura ${ }^{5}$ : 1 . Ambas ocurren en un espacio delimitado y definido para cometerla. 2. Las dos se fundamentan en el control de actividades o necesidades básicas, por ejemplo, el tiempo, la movilidad, el sueño, la alimentación. 3. Ambas logran la despersonalización, la desmoralización y el aislamiento de las víctimas. 4. Tienen en común el uso de las violencias físicas, psicológicas y sexuales. 5. El victimario puede jugar un rol de bueno y malo, a la vez que es todopoderoso ${ }^{6}$. 6. En ambas formas de violencia la dinámica de la psiquis de las víctimas tiende a la disociación, en la cual la víctima se reconoce como objeto de la violencia y no como sujeto, sumado a que pueden ocasionar psíquicamente autodestrucción, desvalorización, confusión en las relaciones que se establecen y culpabilidad. 7. Ambas violencias desencadenan un efecto en el conjunto de la sociedad, razón por la que Falquet plantea que la violencia contra las mujeres es una institución social central, un mecanismo para mantener relaciones sociales de dominación y explotación que estructura el sistema social. Es decir, "un dispositivo material de mantenimiento de la opresión de las mujeres”(Falquet, 2017).

Jules Falquet hace parte de las feministas materialistas que, siguiendo a Collete Guillaumen, plantean que la "clase mujer" es propiedad de la "clase hombre"; que las mujeres son bien público y en la cotidianidad de una relación de pareja se "devela la naturaleza específica de la opresión de las mujeres" (Falquet, 2017, p. 22).

\footnotetext{
${ }^{5}$ En un sentido similar,ver Copelon (1994).

${ }^{6}$ En el campo de la salud mental, las dinámicas propias de estas formas de violencia se han desarrollado desde el concepto de ciclo de la violencia (Garzón, 2006).
} 
El feminismo materialista explica la apropiación del cuerpo de las mujeres bajo lo que denomina relaciones de sexaje, en el que apropia el tiempo para el cuidado, se apropia el cuerpo para la obligación sexual, etc. En palabras de Falquet(2017):

El uso de un grupo por parte de otro, su transformación en instrumento, manipulado y utilizado a fines de incrementar los bienes (de allí igualmente la libertad, el prestigio) del grupo dominante, o incluso sencillamente — lo que es el caso más frecuente - a fines de hacer su sobrevivencia posible en mejores condiciones que las que conseguiría reducido a sí mismo, puede tomar formas variables.( p. 26)

En tanto posesión de los varones, tenemos el deber de "uso y goce" por parte de estos y, en el marco de este mandato social, la violencia que se ejerce contra las mujeres hace parte del repertorio de relacionamiento que es tolerada, despreciada y disminuida. La justicia la presenta, a lo sumo, como un delito secundario.

En conclusión, conceptualmente partimos de la premisa de que la violencia contra las mujeres cometida por parejas y exparejas es un tipo de violencia desencadenada por estructuras de dominación y discriminación, estructural y cultural, simbólica, moral y homologable a la tortura, es decir, una violencia con características propias que requiere de un tipo de respuesta que atienda a sus dinámicas. Por ello, asumir quela violencia que ocurre al interior de la familia es igual a aquella cometida por parejas y exparejas contra las mujeres, puede implicar el ocultamiento de unaproblemática social particular. Ese debate y sus efectos son más evidentes cuando se analiza la respuesta legal y judicial para enfrentar esta forma de violencia. Sobre ello nos referiremos a continuación.

\section{Los debates legales en Colombia en torno a la violencia contra las mujeres y en la familia.La normativa y el debate sobre la familia en la ley}

El Estado colombiano ha ratificado la Convención sobre la Eliminación de todas las Formas de Discriminación contra la Mujer (CEDAW) (OACDH, 1979)yla Convención Interamericana para Prevenir, Sancionar y Erradicar la Violencia contra la Mujer (Convención de Belém do Pará) 
(CIM, OEA, 1994), que condenan cualquier comportamiento de discriminación contra la mujer, incluidas las violencias en su contra y que obligan a los Estados a adoptar medidas inmediatas y progresivas con el fin de garantizar los derechos humanos de las mujeres. En sintonía con dichos compromisos, la Constitución de 1991 establece la responsabilidad del Estado frente a la igualdad real y efectiva para sus ciudadanos y ciudadanas, así como el compromiso estatal de generar políticas en favor de los grupos discriminados (Chaparro, 2017).

En Colombia las mujeres cuentan con un marco normativo sobre el derecho a una vida libre de violencias. Desde la Ley 1257 de 2008 se estableció el funcionamiento de mecanismos de atención y medidas de protección y prevención de las violencias y se creó el agravante por el asesinato de mujeres por el hecho de serlo. Luego, con la Ley 1761 de 2015, se creó el delito de feminicidio, se fortaleció la investigación judicial desde la obligación de debida diligencia, y se establecieron medidas para la prevención y la adopción de un Sistema Nacional de Estadísticas sobre Violencia Basada en Género ${ }^{7}$. Finalmente, en el 2019 se promulgó la Ley 1959 para ampliar lo que jurídicamente se entiende como violencia intrafamiliar e incluir la protección para las víctimas - como ex parejas sin hijos- que por interpretación jurisprudencial habían quedado fuera de la protección.

Pese a estos desarrollos normativos, persiste la brecha entre la ley y la realidad de las mujeres, lo cual se evidencia tanto en la discriminación como "con la permanente ocurrencia de violaciones a sus derechos humanos y la impunidad que las cubre"(Grupo de Monitoreo para la Implementación de la CEDAW en Colombia, 2019, p. 9).

El afrontamiento de esa impunidad y la brecha entre la norma y la realidad han generado posturas variadas en lo que se refiere a las formas adecuadas de enfrentar, en materia de justicia, la cuestión de la violencia contra las mujeres cometida por parejas y exparejas. Encontramos dos posturas prevalentes y en apariencia excluyentes: por un lado, quienes reclaman una completa

\footnotetext{
7 "Dentro del año siguiente a la promulgación de la presente ley, el Departamento Nacional de Estadísticas (DANE), en coordinación con el Ministerio de Justicia y del Derecho y el Instituto de Medicina Legal y Ciencias Forenses (INMLCF), adoptarán un Sistema Nacional de Recopilación de Datos sobre los hechos relacionados con la violencia de género en el país, en orden a establecer los tipos, ámbitos, modalidades, frecuencia, medios utilizados para ejecutar la violencia, niveles de impacto personal y social, medidas otorgadas, servicios prestados y estado del proceso judicial, para la definición de políticas públicas de prevención, protección, atención y reparación de las víctimas de la violencia de género". (Artículo 12, Ley 1761 de 2015)
} 
judicialización penal a través de la justicia retributiva y, por otro, quienes consideran que es la subsunción del daño a través de la justicia restaurativa el camino óptimo para dar respuesta.

Las primeras posturas — de justicia retributiva - plantean que el Estado tiene la obligación de castigar a los perpetradores de la violencia porque no hacerlo no solo propicia dicha violencia, sino que la normaliza y genera impunidad que refuerza la desigualdad. Estos enfoques consideran que el principal obstáculo para el cumplimiento de las normas está en la práctica judicial y en el abordaje de las leyes de violencia, particularmente porque estas se centran en combatir la violencia y no analizan la subordinación y dominación que subyace a la misma, despolitizando así la problemática e interpretando el género como neutral. Otro obstáculo del derecho penal está asociado a que insta a que las víctimas denuncien sin que se garantice la protección efectiva o que las mujeres puedan prescindir de dicha protección cuando lo consideren oportuno (Gorjón, 2010). El derecho internacional de los derechos humanos se ubica en esta línea de acción y muchas organizaciones sociales feministas también buscan una respuesta penal efectiva para esta violencia.

En la segunda posturaencontramos otras autoras que proponen, en cambio, la despenalización de la violencia doméstica y el uso ya no de la justicia retributiva sino restaurativa. Las autoras que plantean la vía restaurativa argumentan que con ello se devuelve el poder a las manos de las mujeres y, si bien no se repara el crimen, sí se reparan los daños (Goodmark, 2019, p. 147).Señalan que el daño psicológico que produce la violencia en las mujeres se asocia con el trastorno de estrés postraumático (TEPT), situación que repercute en las dificultades para abandonar relaciones abusivas. Incluso se ha planteado que las leyes que sancionan la violencia contra las mujeres cometidas por parejas y exparejas no consideran estas complejidades, por ejemplo, las separaciones forzadas o la obligatoriedad de la intervención estatal a través de medidas de protección no son prácticas perfectas ya que podrían generar una recurrencia de la violencia. Además, en consonancia con los planteamientos del feminismo materialista, estas autoras señalan una selectividad en la aplicación de estas normas que está mediada por estructuras clasistas y racistas (Kim, 2020). Estas posturas restaurativas prefieren una mediación legal más que una penalización de la violencia, basándose en la idea de que cada persona es 
capaz de actuar en su propio interés y por ello, las mujeres deberían poder elegir cómo resolver el problema doméstico (Britto, 2005; Carroll, 2012).

De cara a esos debates, en Colombia el camino preponderántemente elegido por el Estado y por algunas organizaciones sociales feministas con capacidad de incidencia en la configuración de las normas ha sido la penalización de la violencia contra las mujeres y el uso del aparato punitivo del Estado. Su alcance y límites los presentaremos a continuación.

En Colombia no existe una normativa penal específica — un delito- que regule la violencia contra las mujeres basada en el género, salvo que resulte en tentativa de feminicidio o feminicidio. Existen tipos penales generales agravados cuando se cometen contra una mujer por el hecho de serlo — como las lesiones personales o la violencia intrafamiliar - y regulaciones que buscan desde la prevención, protección y atención disminuir su incidencia en el país. En otras palabras, aunque cualquier acto de violencia contra las mujeres es susceptible de ser judicializado, no existe un tipo penal autónomo que se concentre en la violencia contra las mujeres (salvo el ya mencionado feminicidio).

Pese a que la violencia cometida por parejas o exparejas se puede dar en cualquier ámbito y configurar diversos delitos, en Colombia la respuesta al fenómeno en el campo penal se ha dado principalmente a través de la tipificación de la violencia intrafamiliar, el feminicidio y la interpretación del fenómeno por parte de las Altas Cortes.

Luego de la Constitución de 1991 han sido aprobadas seis normas que se refieren a la violencia contra las mujeres y dentro de ella la cometida por parejas y exparejas ${ }^{8}$. En un inicio (1996 y 2000), las normas regularon los mecanismos de protección en casos de riesgos; en 2008 se promulgó la Ley 1257 que reconoció y definió la violencia contra las mujeres y desarrolló medidas para enfrentarla en los campos de la prevención, protección y sanción; en 2012 se consideró que cualquier tipo de violencia contra las mujeres sería oficiosa (no dependiente de la

\footnotetext{
${ }^{8}$ Son las Leyes 294, 575, 1257, 1542, 1761 y 1959 (Congreso de la República, 2019; Ley 294, 1996; Ley 575, 2000; Ley 1257, 2008; Ley 1542, 2012; Ley 1761, 2015). Además, deben contemplarse otras normas como la Ley 1719 (Ley 1719 de 2014, 2014), que puede ser aplicada cuando se comete violencia sexual en contra de una pareja o expareja.
} 
denuncia por parte de la víctima) y no conciliable; en 2015 se tipificó el feminicidio y; en 2019 se modificó el delito de violencia intrafamiliar. En el marco de los debates de estas leyes, ha estado permanentemente abierta la cuestión de si la violencia intrafamiliares un tipo penal de investigación oficiosa y si puede ser conciliado.

La última norma — la Ley 1959 de 2019—, como ya se señaló, tuvo como preámbulo una decisión de la Corte Suprema de Justicia de 2017, en la cual el Alto Tribunal concluyó que la violencia perpetrada entre exparejas, independientemente de si tenían hijos o no, no constituía violencia intrafamiliar sino lesiones personales. Su argumento central fue que el núcleo familiar "supone la existencia real y no meramente formal de una familia en su conjunto, su unión, su cotidianidad, su vínculo estrecho, su afectividad y su coexistencia diaria (...). Si el núcleo supone unión y conjunción, se desvirtúa y pierde su esencia cuando hay desunión o disyunción entre sus integrantes" (Corte Suprema de Justicia, 2017, p. 19).

Determinar que la violencia contra las mujeres cometida por las exparejas no constituía violencia intrafamiliar sino lesiones personales abrió un gran debate en el país, en el cual tanto organizaciones sociales de mujeres como funcionarias del Estado alertaron sobre el riesgo de feminicidio y los vacíos que generaba la sentencia ${ }^{9}$. Inclusive, diversas voces institucionales y no institucionales señalaron el carácter no vinculante de esta decisión ${ }^{10}$.

Una vez la noticia fue divulgada, se pusieron en evidencia sus impactos. La Procuraduría y representantes de las organizaciones de mujeres del Comité de seguimiento a la Ley 1257 de 2008 emitieron un comunicado conjunto en el que se lee:

\footnotetext{
${ }^{9}$ Los riesgos implicaban "que la sociedad quedará expuesta a que a) aumente notablemente el subregistro del delito de VIF, lo cual impactará negativamente su valoración cómo un problema de salud pública y como la más numerosa y sistemática violación de DH de las mujeres b) precluirán procesos de investigación por VIF, dado que la sanción penal por LP [lesiones personales] es menor que por VIF, al tiempo que se suspenderán órdenes de captura por VIF que estaban en curso y se alegaran nulidades buscando terminar estos procesos c) a diferencia de la VIF, en el delito de lesiones personales no proceden medidas de aseguramiento y en principio no procede la privación de la libertad; se exige denuncia, lo que implica que no se adelante de manera oficiosa, dándosele tratamiento de querellable, desistible y conciliable; la pena es menor d) las mujeres no tendrán acceso al tratamiento integral en salud como víctimas de VIF sino de LP, y por tanto no se aplicarán los protocolos definidos para ello" (Colombia más positiva, 2017). Ver también Secretaría de la mujer y equidad de género. Gobernación del Atlántico (2017).

${ }^{10}$ Algunas de esas voces fueron las de la Gobernación de Antioquia y la Alcaldía de Medellín (Colombia más positiva, 2017), la Gobernación del Atlántico (Secretaría de la mujer y equidad de género. Gobernación del Atlántico, 2017) (Procuraduría General de la Nación y Representantes de las organizaciones de mujeres del Comité de seguimiento a la Ley 1257 de 2008, 2017).
} 
hemos tenido conocimiento de las consecuencias negativas de esa decisión, en cuanto los operadores de justicia a partir del fallo de la Corte Suprema están remitiendo los casos de violencia intrafamiliar a las fiscalías que conocen de lesiones personales - sin los agravantes de la ley 1257-, quienes dejan en libertad a los agresores, obligan a las mujeres a conciliar y las exponen a mayores riesgos, incluido el feminicidio. Esta decisión beneficia exclusivamente a los agresores y pretende obviar la superación del carácter querellable de la violencia intrafamiliar como respuesta a la resistencia discriminatoria de las autoridades para aceptar la prohibición de desistimiento y conciliación en estos casos. Se toma un distractor sobre la composición familiar, —que ya está clara en la ley 1257- y que no es el enfoque adecuado de análisis como sí lo es la temática de violencias hacia las mujeres.(Procuraduría General de la Nación y Representantes de las organizaciones de mujeres del Comité de seguimiento a la Ley 1257 de 2008, 2017)

Eran los riesgos, vacíos y consecuencias negativas lo que causaba el rechazo de las organizaciones sociales y algunas instituciones. El temor a la desprotección era justificado: en Colombia la respuesta judicial a la violencia contra las mujeres ha tendido a estratificar dichas violencias en aquellas que merecen atención y otras que no son acreedoras de vigilancia estatal demostrando, a su vez, qué tipo de relaciones y violencias son importantes y cuáles no. Así, se ha priorizado la respuesta en tres circunstancias: la familiar, el conflicto armado y las violencias de alto impactoque incluyen los ataques con agentes químicos, la violencia sexual y el feminicidio (Chaparro, 2020). Todo tipo de violencia y mujeres que se encuentren por fuera de estas esferas difícilmente cuentan con apoyo estatal, lo cual revela mujeres y espacios que importan y que no.

Así que excluir de la noción de núcleo familiar a las exparejas las dejaba en un ámbito de desprotección en el escenario jurídico colombiano puesto que, aunque los niveles de impunidad son altísimos y la garantía para las víctimas de violencia intrafamiliar tampoco es la adecuada, al menos existe un cuerpo normativo algo más robusto y con mayor capacidad de respuesta. El panorama era desolador. 
En consecuencia, la propia Fiscalía presentó al Congreso una iniciativa para modificar el delito de violencia intrafamiliar en el Código Penal, el cual resultó en la aprobación de la Ley 1959 de 2019. Dicha norma definió el delito de violencia intrafamiliar como "El que maltrate física o psicológicamente a cualquier miembro de su núcleo familiar, incurrirá, siempre que la conducta no constituya delito sancionado con pena mayor (...)” y amplió su protección a las siguientes relaciones:“a) cónyuges o compañeros permanentes, aunque se hubiesen separado o divorciado; b) El padre y la madre de familia, aun cuando no convivan en el mismo hogar, si el maltrato se dirige contra el otro progenitor c) Quien, no siendo miembro del núcleo familiar, sea encargado del cuidado de uno o varios miembros de una familia en su domicilio, residencia o cualquier lugar en el que se realice la conducta. d) Las personas con las que se sostiene o hayan sostenido relaciones extramatrimoniales de carácter permanente que se caractericen por una clara e inequívoca vocación de estabilidad”.

En otras palabras, la ampliación de la violencia intrafamiliar cobijó los casos de parejas y exparejas solo cuando estos sean o hayan sido cónyuges o compañeros permanentes, tengan o hayan tenido hijos en común o en los casos que haya habido una relación extramarital con vocación de estabilidad.

Aunque en apariencia la Ley 1959 de 2019 dio por finalizado el debate, lo cierto es que esta respuesta es sintomática de tres problemas que requieren ser revisados: 1. Qué tipo de relaciones y familias ingresan en la protección judicial y, con ello, qué tipo de familias son construidas como legítimas. 2. Qué ocurre con los casos de violencias cometidas por parejas y exparejas que no logran reunir las condiciones enunciadas en la norma: violencia entre novios, convivencias cortas, relaciones sin vocación de estabilidad. 3. Qué hacer con el sinnúmero de casos de violencias contra las mujeres que no se encuentran en el ámbito de la familia, el conflicto armado o que no son consideradas de alto impacto, como por ejemplo, violencias en el ámbito laboral, educativo, comunitario, entre otras. En estos tres problemas no se trata solo de la respuesta judicial, sino de la creación de sujetos considerados como 'dignos' de ser protegidos, de la formación jurídica de una jerarquía entre violencias, así que la pregunta que se mantiene es ¿cuáles son condiciones personales y relacionales que las mujeres deben alcanzar para ser 
consideradas dignas de protección? Una aproximación a esa respuesta la presentaremos a partir del estudio de 12 sentencias.

\section{Estudio de sentencias sobre violencia contra las mujeres cometida por parejas y exparejas en Bogotá}

La violencia contra las mujeres, incluida la cometida por parejas o exparejas, ha sido elevada a la categoría de asunto de derechos humanos, es decir, de interés público cuya reacción por parte del Estado debe darse al más alto nivel y garantizando una debida diligencia ${ }^{11}$. El derecho y el Estado juegan un lugar protagónico en el afrontamiento de la problemática, no solo por su actuación sino porque operan como una tecnología de género, es decir, como un mecanismo de producción y reproducción del género (Núñez, 2019). Las normas y su aplicación en casos de violencias contra las mujeres por parejas y exparejas parten de la idea de la existencia de un sujeto generizado (hombre y mujer, en singular) y lo produce simultáneamente en el proceso de revisión de sus denuncias, reforzando sus características y generando efectos prácticos en la vida de las víctimas y en general de la sociedad. Qué tipo de familia y de relaciones familiares se amparan y qué clase de mujeres y comportamientos son protegidos,son parte de las cuestiones que deben ser analizadas para verificar si las respuestas estatales realmente cumplen la finalidad que se propusieron, esto es, desestructurar las relaciones de poder inmersas en la violencia contra las mujeres.

Para realizar el análisis de las formas como el derecho se pone en práctica en situaciones reales, seleccionamos de manera aleatoria 12 sentencias referidas a hechos de violencias contra las mujeres cometidas por parejas o exparejas ocurridos en Bogotá. Las sentencias fueron emitidas entre los años 2018 y 2020, es decir, con posterioridad al debate planteado por la Corte Suprema de Justicia en 2017 y, en algunos casos, a la Ley 1959 de 2019.Estas sentencias se encontraban en firme ${ }^{12} \mathrm{y}$, por tanto, son de carácter público. Dado que es inexistente el

\footnotetext{
${ }^{11}$ Para profundizar en esta cuestión ver Lemaitre (2008).

${ }^{12}$ Es decir, que la sentencia ya no puede ser debatida porque finalizó todo el ciclo judicial y ninguna de las partes interpuso recursos ante otras instancias. Dado este carácter, las sentencias judiciales son públicas y no tienen limitaciones de confidencialidad. La búsqueda, selección y recopilación de los expedientes de los casos fue realizada por la estudiante de la Maestría en Defensa de los Derechos Humanos de la Universidad Santo Tomás, Sandra Pinilla, a quien agradecemos su trabajo y generosidad.
} 
mecanismo de revisión de los archivos bajo la categoría de violencias cometidas por parejas y exparejas, se priorizaron los tipos penales de violencia intrafamiliar y feminicidio ${ }^{13}$.

Estos casos podrían ser vistos como exitosos porque lograron una condena en contra de los agresores, sin embargo, más que la pena de prisión, nos interesa profundizar en sus argumentos, en las formas como se estructuran y jerarquizan tipos de mujer y de conductas a proteger, y en las condiciones excepcionales que reúnen para ser acreedores de protección judicial en un ambiente de casi total impunidad.

Los criterios de análisis que seleccionamos fueron: 1. Estudio del contexto, 2. Estereotipos presentes en las sentencias, 3. Tipo de mujer y familia que protege, 4. Participación de la víctima en el proceso, 5. Medidas de reparación y 6. Medidas de protección. Cabe aclarar que, como se mencionó en los apartados anteriores, partimos de la premisa de que las violencias estudiadas en estas sentencias configuran violencia contra las mujeres por el hecho de ser mujeres y este aspecto es transversal a todos los criterios señalados.

Como descripción general de los hechos de los 12 casos, tenemos que 10 corresponden a violencia de pareja en unión heterosexual, 1 en la frontera entre pareja y expareja ${ }^{14}$ y 1 de violencia fuera de la familia ${ }^{15}$. Del total de casos, 11 fueron conocidos por denuncia directa de la víctima y 1 por denuncia de la madre de la víctima (caso 8). De los 12 casos, 11 concluyeron con sentencia condenatoria y 1 con renuncia de la acción penal por principio de oportunidad a favor del agresor, luego de encontrarse en un 'período de prueba' de tres meses (caso 8). En 3 casos los agresores aceptaron cargos, lo que los hizo beneficiarios del descuento de dicha aceptación hasta la mitad de la pena (casos 10 a 12); en un caso se llegó a un preacuerdo aplicando la circunstancia de la ira al caso (caso 7). Todos corresponden a violencia física en contra de las víctimas, aunque hay evidencia de otras formas de violencia - psicológica, económica e incluso sexual- que no fueron tomadas en cuenta y que podrían ser constitutivas de otros delitos como la tortura.

\footnotetext{
${ }^{13}$ La información detallada de las 12 sentencias estudiadas se encuentra en la sección de bibliografía.

${ }^{14}$ Se encontraban en proceso de separación aunque seguían conviviendo. Caso 9. Dentro de la violencia entre parejas y exparejas hay mecanismos de violencia que se diferencian, aunque en ocasiones resulta difuso determinar sus fronteras (Tepichin, 2019, p. 60).

15 Se trata del caso 6 catalogado como "amigos especiales".
} 
Sobre los seis criterios elegidos procedemos a continuación a presentar algunos hallazgos.

En relación con el análisis de contextoefectuado, ninguno de los casos realizó un estudio sobre las relaciones de poder presentes, el tipo de relacionamiento entre víctima y victimario y las causas subyacentes de la violencia originadas en la discriminación. Aunque en la totalidad de casos tramitados por violencia intrafamiliar se aplicó el agravante por recaer sobre una mujer ${ }^{16}$, en ninguno de ellos se hizo un análisis sobre la connotación de género del delito ${ }^{17}$. El único caso que contempló una enunciación de tratarse de un delito basado en el género fue el tramitado por tentativa de feminicidio entre 'amigos especiales' (caso 6).

En estos casos el aparato judicial presupone la existencia de un sujeto mujer que debe ser protegido, lo cual pareciera darle una mayor garantía de derechos, no obstante, obviar del análisis las relaciones de poder y el lugar del género en la violencia, tiene como efecto homologar este tipo de violencia a una ordinaria. El fin último de la causa de los movimientos de las mujeres por ampliar la protección en la norma ha sido el reconocimiento de la particularidad de este tipo de violencia, la cual se invisibiliza con prácticas judiciales que anulan su relevancia.

Aunque en la mayoría de procesos existieron pruebas sobre un posible ciclo de violencia por hechos reiterados (casos 1, 3, 5,7, 9, 10, 11, 12), los hechos investigados y por los que se condenóse redujeron al que causó la denuncia y no a los previos o posteriores ${ }^{18}$. Además, aunque en la mayoría hubo evidencia de otros tipos de violencia que incluyen privación de la libertad, violencia psicológica, económica y sexual, los juzgados únicamente se concentraron en el análisis de la violencia física.

\footnotetext{
${ }^{16}$ El artículo 229 del Código Penal establece en su segundo inciso un agravante "cuando la conducta recaiga sobre un menor, adolescente, una mujer, una persona de sesenta (60) años, o que se encuentre en situación de discapacidad o disminución física, sensorial y psicológica o quien se encuentre en estado de indefensión o en cualquier condición de inferioridad".

${ }^{17}$ Esto pese a que ocho casos tienen sentencia posterior a 1 de octubre de 2019, fecha en la cual la Corte Suprema de Justicia (Sentencia SP4135-2019, 2019) indicó que para aplicar el agravante es necesario estudiar la motivación de género presente en los hechos.

${ }^{18}$ Como excepción se encuentra el caso 6 que es tentativa de feminicidio en una relación no familiar catalogada como de 'amigos especiales'. Allí el Juzgado señaló que el acto de violencia era "culmen de un ciclo de violencia física y psicológica que antecedió el crimen contra ella, por razón directa de la relación sentimental que llevaban y el hecho de no querer la señora formalizarla”.
} 
En los casos en los que hubo aceptación de los cargos, no fueron tenidas en cuenta otras pruebas existentes que podrían ampliar el análisis e inclusive reconocer la existencia de otros delitos asociados como la tortura, la violencia sexual o la tentativa de feminicidio. El caso 12, dada su extrema crueldad, lo ejemplifica: la víctima señaló la ocurrencia de violencia sexual en varias oportunidades incluida la del día de la denuncia, informó que el agresor la atacó con un perro pitbull y hubo prueba de Medicina Legal sobre graves lesiones en su cuerpo derivadas de dicha violencia, pese a lo cual la condena fue por violencia intrafamiliar agravada, con disminución de la pena del 50\% por aceptación de cargos, lo cual arrojó una pena total de 36 meses $^{19}$.

Así las cosas, la falta casi total de investigación del contexto en que se dan las violencias contra las mujeres cometidas por parejas o exparejas tiende a desconocer las particularidades de este fenómeno y a mantener en un lugar intacto las relaciones de poder que le dieron lugar. Pese a que la mayoría de casos finalizaron con sentencia condenatoria, esta no logró dar un mensaje rotundo a la sociedad de intolerancia frente a estas conductas.

Esto nos lleva a la cuestión de los estereotipos presentes en las sentencias, es decir, de posibles preconceptos "de atributos o características poseídas o papeles que son o deberían ser ejecutados por hombres y mujeres respectivamente" ${ }^{20}$ y que son la base de las decisiones judiciales u orientan el análisis judicial.

Dado que la revisión del contexto es prácticamente nula en todos los casos y que el estudio se detiene en las circunstancias de modo, tiempo y lugar aisladas de un único hecho y no de un conjunto de situaciones que explican la violencia, la aparición de estereotipos no es explícita. Y es justamente esa ausencia de análisis y el uso de ciertas figuras - como la disminución de responsabilidad por ira (caso 7) - las que demuestran el principal estereotipo presente: la

\footnotetext{
${ }^{19}$ Dice el informe médico-legal: “es la $6^{\circ}$ vez que le pega y que la ha abusado sexualmente, en múltiples ocasiones de manera vaginal, anal y oral. Refiere incontinencia de esfínter anal desde el inicio del abuso, refiriendo además abuso verbal diario y que ya ha denunciado con anterioridad" (caso 12).

${ }^{20}$ Esta definición ha sido ampliamente desarrollada por la Corte Interamericana de Derechos Humanos Ver Corte Interamericana de Derechos Humanos (2009, párr. 401; 2015, párr. 180-183; 2016, párr. 187; 2017, párr. 169; 2018a, párr. 235; 2018b, párr. 213).
} 
subvaloración de la violencia contra las mujeres en el ámbito tradicionalmente considerado privado.

Pese a existir elementos dentro de los procesos que pueden ser analizados como violencia basada en género, se desconocen abiertamente: expresiones como "perra" o "puta" (caso 1), la expresión explícita de que "si no era para él, no sería para nadie" (caso 6), la separación de roles entre proveedor y cuidadora que es considerada "normal" (caso 9) o el uso de violencia sexual (caso 12), entre otras formas de violencia. El no asociar esta violencia como una violencia basada en el género constituye una forma de discriminar a las mujeres puesto que tiene por efecto privar a las víctimas de su derecho a la verdad sobre las causas de la violencia que las afecta ${ }^{21}$.

En otras palabras, esta práctica judicial que en apariencia le da relevancia a la violencia al aplicar un agravante normativo, al estar vacío de contenido por carecer de un análisis de género, devuelve al ámbito privado la gravedad de la conducta y hace de la violencia un asunto de ruptura de la armonía familiar ${ }^{22}$. Así que los "papeles que son o deberían ser ejecutados por hombres y mujeres" son los de victimario y víctima, puesto que no hay un reproche de las estructuras de dominación que soportan la violencia, lo cual termina legitimándola y con ello los roles asociados a esa estructura.

Y esto es interesante porque en todos los casos hay apariencia de justicia, salvo el caso 8 en que se aplicó principio de oportunidad ${ }^{23}$. Todos los demás tuvieron sentencia condenatoria.

\footnotetext{
${ }^{21}$ Es importante recordar que los conceptos jurídicos de discriminación y violencia contra las mujeres no exigen la intencionalidad para ser configurados. Es posible que se configure violencia y discriminación aún cuando el agente esté actuando de buena fe, puesto que se requiere que la conducta esté fundamentada en estereotipos que pueden ser o no conscientes. Un buen ejemplo de ello se encuentra en el caso de IV contra Bolivia en el que la Corte Interamericana de Derechos Humanos (2016) conoció de una esterilización sin consentimiento practicada por un médico en el marco de una cesárea, la cual estuvo basada en preconceptos sobre la toma de decisiones en materia reproductiva. La voluntad del médico de proteger a la víctima de una posible muerte en caso de quedar nuevamente en embarazo fue irrelevante.

${ }^{22}$ Es importante rescatar en este punto a Elizabeth Jelin (2010) en su análisis sobre la distinción entre lo público y lo privado cuando señala que la diferenciación tajante entre esas esferas "lleva a mutilar la ciudadanía de las mujeres" ( p. 172).

${ }^{23}$ En el caso 8 se trató de un caso de violencia de pareja en el cual se suspendió la acción penal a condiciones de conducta y resarcimiento acordadas con la víctima: compromiso para participar en terapias para control de ira; compromiso de no repetición de agresiones; manifestación pública de perdón y arrepentimiento; indemnización por 210.000 pesos; pago de tratamientos para la víctima, pago proceso terapéutico (6 individuales para cada uno y 1 conjunta porque siguen siendo pareja); residir en un lugar determinado e informar cambios de domicilio; demostrar
} 
Los casos de violencia intrafamiliar fueron sentenciados entre 38 y 86 meses: el caso 1 recibió pena de 86 meses, de 72 meses los casos 2, 3, 4, 5, 9; y de 36 meses en los casos 10, 11 y 12 porque hubo aceptación de cargos y, por ende, rebaja de pena del 50\%. En el caso 6 hubo aceptación de cargos y la pena fue de 93,75 meses por tentativa de feminicidio. En el caso 7 hubo preacuerdo con el agresor y la condena fue de 18 meses en violencia intrafamiliar por aplicar la disminución de responsabilidad por la circunstancia de la ira, lo que se traduce en afirmar que la víctima provocó al agresor y este reaccionó (caso 7$)^{24}$.

La pregunta que surge es ¿por qué habiendo 'justicia' señalamos que esta es insuficiente? Básicamente tratamos de decir que una condena carece de relevancia social si está desprovista de un análisis que devuelva la dignidad a la víctima, si falta a la verdad en cuanto a los contextos de violencia previos y posteriores y si no tiende a reprochar e intentar desestructurar las relaciones de dominación en la que se basan estas relaciones desiguales de poder.

Es una justicia aparente porque desconoce las circunstancias en las que se desarrolla e invisibiliza la violencia contra las mujeres. El caso 12 es una buena muestra de esto: ante un ciclo de violencia gravísimo y cruel que involucra violencia física, psicológica, económica y sexual, la respuesta judicial es rebajar la pena a la mitad porque el agresor aceptó los cargos, en vez de reconocer una posible tentativa de feminicidio cuando el agresor ataca a la víctima con un perro, además, no investiga la violencia sexual que ya ha dejado huellas a largo plazo en el cuerpo de la víctima. Disfrazar la impunidad con una apariencia de justicia es subvalorar la violencia y constituye también violencia institucional ${ }^{25}$.

Analizar estos casos que parecen 'exitosos' es revelador porque nos conduce a una pregunta significativa ¿Qué tienen de particular estos casos que logran finalizar con sentencia condenatoria

buena conducta; realizar un taller de violencia intrafamiliar. Posteriormente, se desarrolló una audiencia de renuncia de la acción penal por demostración del cumplimiento de esos compromisos, en la que la víctima estuvo presente.

${ }^{24}$ Según la Corte Suprema de Justicia deben concurrir tres elementos para que pueda hablarse de ira: ““( $(i)$ un acto de provocación grave e injusto, (ii) la reacción del agente bajo un estado anímico alterado -ira o intenso dolor-, y (iii) una relación causal entre ambas conductas" (Auto AP4737, 2015; Sentencia SP5392-2019, 2019). El caso 7 es interesante porque la pena de 18 meses se justifica "debido a la gravedad de los hechos, así como a la proclividad o reincidencia".

${ }^{25}$ El concepto de violencia institucional ha sido desarrollado por la Corte Constitucional. Ver Corte Constitucional (2017; 2018). 
y que se vuelven excepcionales en el universo de casos donde la impunidad supera el 85\%? (El Tiempo, 2019). Tres cosas: el tipo de mujer y familia que protegen, el tipo de víctima que aparece, y el tipo de agresor o tercero que confirma lo dicho por la víctima.

Frente al tipo de familia y mujer que protegen estas sentencias, encontramos varios elementos. En primer lugar, la mujer representa en la mayoría de los casos la figura de la madresposa que Marcela Lagarde (2003) ha caracterizado en el proceso de construcción del sujeto mujer en razón de sus mandatos de cuidado y obediencia en la maternidad y la conyugalidad. Según Lagarde:

Para que la mujer exista es necesaria la preexistencia del hombre . Ella sólo existe social e individualmente por esta relación . En cambio el hombre es en sí mismo. De ahí, la importancia del lazo conyugal de las mujeres . De ahí que deban ser esposas para existir. Este nexo es síntesis de la relación de dependencia vital de las mujeres con los hombres, en este caso de monogamia femenina, se espera que cada mujer se haga de un esposo.

La mujer sola es imaginada como la mujer carente, le falta algo, le falta el dador de la vida social, le falta el hombre.(Lagarde, 2003, p. 367).

Es justamente esta relación constitutiva del sujeto femenino la que aparece protegida en las sentencias estudiadas. En todos los casos analizados es la correcta disposición del lazo maternoconyugal el que se protege y, con él, los mandatos de lo femenino y lo masculino ${ }^{26}$. No en vano es el bien de la "armonía y unidad familiar" el que se protege en el caso de la violencia intrafamiliar:

en síntesis, lo que el tipo penal protege no es la familia en abstracto como institución básica de la sociedad, sino la coexistencia pacífica de un proyecto colectivo que supone el

\footnotetext{
${ }^{26}$ Resulta interesante que la renuncia a la acción penal en el caso 8 a través de un principio de oportunidad se justifica por la Fiscalía "con el fin de proteger a la familia como núcleo esencial de la sociedad, por cuanto el núcleo familiar que se rompió en su momento en el año 2016 ya se encuentra debidamente reconstruido y que ellos continúan siendo pareja".
} 
respeto por la autonomía ética de sus integrantes.(Corte Suprema de Justicia, 2017 citada en el caso 5).

Es decir, no se protege a los sujetos incorporados en una relación familiar, sino a la relación misma, lo cual relega a los sujetos a un estatus de dependencia con dicha relación que, dada la sujeción de las mujeres, las mantiene en posición de dominación, desde la perspectiva de la apropiación de sus cuerpos, en los términos ya referidos de Falquet. El caso 4 lo ejemplifica al considerar "reprochable escena de agresión a una mujer, madre de familia en frente de uno de sus menores hijos" (caso 4).

Para considerar que el delito es contra la armonía familiar se encuentran argumentos como "Cualquiera ofensa verbal que atente contra la integridad de una persona puede conllevar a la vulneración de la unidad y armonía familiar"; “(en) la conducta del acusado ... existió una notable afectación en la armonía y la unidad familiar, logrando incluso que en este caso la familia se desintegrara" (caso No. 4); "la violencia intrafamiliar atenta contra derechos que le pertenecen a la familia en conjunto. La agresión doméstica afecta lo que se ha denominado la "moral familiar", que no es otra cosa, que los principios éticos que mantienen firme los lazos de solidaridad y afecto entre los miembros del núcleo familiar, implica observar una conducta acorde con las normas mínimas que orientan la convivencia armoniosa, como el respeto, el decoro, el pudor, la mutua ayuda y la comprensión" (caso No. 9).

En razón de que la protección del bien jurídico es la armonía y unidad familiar y no la integridad de los sujetos comprometidos en la violencia, el análisis de los hechos se concentra principalmente en demostrar la existencia de un vínculo familiar consistente en el lazo de convivencia afectiva o de convivencia física bajo el mismo techo. Las pruebas de dicho lazo suelen ser las mismas: la aceptación del propio agresor, la denuncia de la víctima o el cuidado de la mujer frente a hijos o hijas en común. De esta forma, dos elementos son claves para probar la unidad familiar: compartir un techo y los hijos al cuidado de la pareja. Y, en muchos de los casos, es justamente el rompimiento de la relación la prueba más evidente de la vulneración del bien jurídico protegido ( $\operatorname{casos} 1,2,3$ y 5). Esta situación es paradojal porque entre los casos 
analizados, en tres de ellos el vínculo estaba roto antes del hecho de violencia a juzgar (caso 1, 4 y 5).

De esta forma, la ley y los jueces protegen un tipo de familia: aquella que comparte un mismo techo o aquella en la que hay un cuidado común de hijos, es decir, un tipo "ideal” de familia. Así, el delito contra la mujer pasa a ser un agravante por el hecho de ser mujer, pero no se detiene en el problema estructural de la violencia sino en probar la ruptura de la unidad familiar.

En este proceso, la configuración del sujeto femenino se basa en dos supuestos primordialmente contradictorios: su condición de víctima débil y su estatus de testigo creíble.

En relación con el primer aspecto: "es la familia, que, de acuerdo a la jurisprudencia de la Corte Constitucional, tiene como objetivo erradicar toda forma de violencia en la familia, aparte de garantizar los derechos de los miembros más débiles de la población, como los menores de edad, las personas de tercera edad y las mujeres" (caso No. 12, cursiva fuera del texto original). Así que la razón de protección de la mujer - y su configuración simultánea- se da bajo la consideración de debilidad característica de los sujetos infantilizados: niños, adultos mayores y mujeres. Esto es lo que explica que en ninguno de los casos se haga un análisis de las condiciones de subordinación de las mujeres ni de las particularidades de las relaciones violentas: la sola idea de su condición sexuada de mujer la hace acreedora de mayor protección porque se la considera más débil.

De otro lado, su comportamiento durante el proceso debe acoger características de un testigo creíble, fundiendo en un solo proceso los requisitos del proceso penal con la configuración del sujeto a proteger. En otras palabras, para que el dicho de la víctima sea creíble y ella sea protegida, la mujer debe ser precisa y coherente: "su relato fue hilado y con una evocación de detalles tal que se pudo reconstruir lo sucedido", se lee en el caso No. 9 o en el caso No 2 "no se notó ánimo alguno de faltar a la verdad, porque incluso su narración gozó de muchos detalles de tiempo, modo y lugar". Aunque reivindicamos que no existe un solo modelo de víctima y que los efectos de la violencia contra las mujeres no son iguales para todas, es claro que el tipo de mujer que se protege cuando se defiende este tipo de testimonio, dista de comprender los efectos 
emocionales y en la salud mental que pueden presentar las víctimas de violencias por el hecho de ser mujeres.

Sumado a lo anterior, aparece el tercer elemento que pareciera ser determinante: la aceptación por parte del agresor o la confirmación de la versión por un tercero. De la totalidad de 12 casos analizados, 5 contaron con aceptación de responsabilidad por parte del victimario, lo que no deja alternativa para una condena (casos 6, 7, 9 a 12) o la aplicación del principio de oportunidad (caso 8). En otros 5 casos, el agresor no aceptó los cargos y se surtió el debate procesal completo y en todos se allegó prueba de médico o policía que corroboraba la versión de la víctima. Así las cosas, es la idea de una víctima coherente - un valor masculino de racionalidad- junto con la palabra del agresor o de un tercero revestido de credibilidad por los dispositivos de la medicina o la labor policial, los que hacen posible condenar la violencia.

Esto nos lleva al cuarto elemento de análisis: la participación de la víctima. Tal como mencionamos anteriormente, un aspecto relevante en las decisiones judiciales fue el testimonio de la víctima donde ella se mostró clara, precisa y congruente, dando detalles de tiempo, modo y lugar. Únicamente en el caso 8, que finalizó con principio de oportunidad donde la relación se mantuvo luego de la violencia, fue la madre de la víctima la que presentó la denuncia. En los 11 casos restantes, la víctima presentó la denuncia directamente. De ellos, en 6 hubo aceptación de responsabilidad y, por tanto, no se fue a juicio, y en 5 se debatió en juicio el proceso y en todos se contó con el testimonio de la víctima.

Esto nos lleva a algo importante: uno de los pilares del reconocimiento de la violencia como un asunto de derechos humanos es que adquiere un carácter oficioso —es decir, que no depende de la denuncia de la víctima- y, por ende, la investigación es un deber del Estado que no puede condicionarse a la participación de la mujer. No obstante, estos procesos nos demuestran que la práctica judicial no es consecuente con lo anterior: o el agresor acepta los cargos o la víctima debe participar en los procesos judiciales y ser una testigo creíble (una “víctima ideal”); si alguna de estas condiciones no se cumple, las probabilidades de lograr una condena son mínimas. 
De esta forma, la víctima es nuevamente objetivizada por el aparato judicial que la instrumentaliza para lograr una condena, sin que sea un sujeto central dentro del desarrollo del proceso. Esto queda más claro cuando se analiza el caso en el que hubo preacuerdo y se aplicó el atenuante de la ira (caso 7). En dicho caso la Fiscalía llegó a un acuerdo con el agresor sin considerar la voluntad de la víctima, o sus intereses de reparación o de protección ${ }^{27}$. En otras palabras, importa la condena pero no importa la víctima, lo que nos lleva a los dos últimos elementos de análisis: las medidas de reparación y las medidas de protección.

En cuanto a las medidas de reparación, en ninguno se interpuso el incidente de reparación integral y los jueces únicamente se limitaron a señalar que las víctimas, la Fiscalía o el Ministerio Público contaban con 30 días para interponerlo. En los casos 3, 7 y 9 ni siquiera el Juzgado le comunicó a la víctima de este derecho.

Desde una perspectiva consecuente con el derecho a la reparación de las víctimas de violaciones a los derechos humanos, su carácter de interés público y el reconocimiento de la discriminación manifiesta en una relación desigual de poder, lo lógico sería que la Fiscalía o el Ministerio Público presentaran la solicitud por la víctima cuando esta no lo hace ${ }^{28}$. Sin embargo, en ninguno de los casos el Ministerio Público participó y la Fiscalía no presentó la solicitud. Así las cosas, salvo el caso que finalizó con principio de oportunidad (caso 8) ${ }^{29}$, ninguna de las víctimas contó con medidas de reparación que atendieran las secuelas físicas, psicológicas y patrimoniales derivadas de la violencia, incluso contando con recomendaciones para ello: en el caso 10, por ejemplo, Medicina Legal sugirió "valoración e inicio de proceso psicoterapéutico para la víctima y núcleo familiar el cual debe ser tenido en cuenta dentro de la investigación" (caso 10).

Esta renuncia a considerar a la víctima como un sujeto de pleno derecho se hace aún más notoria cuando se analizan las medidas de protección. De los 12 casos, únicamente en 3 se

\footnotetext{
27 Sabemos que al respecto ha habido un debate intenso en la jurisprudencia de las Altas Cortes, no obstante, nos interesa señalar acá que independientemente del debate sobre la figura del preacuerdo, las víctimas quedaron invisibilizadas en estos casos. Al respecto ver (Corte Constitucional, 2019).

${ }^{28}$ El artículo 102 del Código de Procedimiento Penal habilita a la Fiscalía y al Ministerio Público a instancias de la víctima a solicitar el incidente de reparación integral.

${ }^{29}$ En el caso 8 se indemnizó con 210 mil pesos a la víctima.
} 
decidieron medidas de protección dentro del proceso penal (casos 1, 10, 12) y en 2 se hizo referencia a la existencia de medidas de protección por parte de la Comisaría de Familia (casos 7 y 8$)^{30}$. Esto es grave, especialmente porque en dos casos en los que no se decretaron medidas de protección Medicina Legal había alertado sobre la necesidad de imponerlas (casos 3, 9), y en otros dos casos valoró el riesgo de violencia mortal y lo clasificó en riesgo extremo "de sufrir lesiones muy graves e incluso la muerte" (casos 6, 11). Esto significa que de los 12 casos, hay información de situaciones de riesgo de violencia en al menos 9, pero dentro del proceso penal la autoridad solo emitió medidas en 3 de ellos.

La falta de protección en la mayoría de los casos, sumada a los elementos vistos anteriormente sobre la ausencia de reparación, la instrumentalización de la participación de la víctima, la prevalencia de la protección del vínculo familiar por encima de la integridad e igualdad de la mujer, dan cuenta de la subvaloración en la justicia penal de la violencia contra las mujeres cometidas por parejas o exparejas, incluso en aquellos casos que podrían considerarse exitosos por finalizar con una condena penal. La consecuencia es que se mantiene intacta la estructura de poder subyacente a la violencia y, con ello, el lugar social de la mujer que la construye como víctima, débil y cautiva de una relación de sujeción como madresposa.

\section{Conclusiones}

El abordaje conceptual de las violencias contra las mujeres permite establecer que la violencia entre parejas y exparejas se caracteriza por ser una violencia estructural de género de carácter cultural basada en las desigualdades históricas construidas socialmente. Dicha violencia puede ser material o simbólica y en muchos casos llegar a constituir tortura. No obstante, la intervención estatal, al considerarla como una forma de violencia intrafamiliar, brinda una respuesta parcial de carácter instrumental centrada en determinar la intención del agresor de causar daño a la "unidad familiar" y no la afectación a la mujer víctima.

\footnotetext{
${ }^{30}$ En el caso 7 se hace referencia de un incumplimiento por tercera vez de la medida de protección impartida, no obstante, se preacuerda reconocer como atenuante de responsabilidad la ira y, en consecuencia, condenar a 18 meses (la pena ordinaria es de 48 a 96 meses de prisión).
} 
La violencia contra las mujeres en relaciones de pareja y expareja, responde a la apropiación y cosificación que se hace de ellas como mujeres, donde se pone de manifiesto las relaciones desiguales de poder dadas desde lo que las feministas materialistas (Wittig, 2010) llamarían el "régimen político de la heterosexualidad, el cual regula, controla y se apropia de las mujeres en tanto grupo social, a la vez que produce estructuras, tanto para perpetuarse, como para dominar en el plano material'(Loaiza, 2017, p. 30). Ninguna de estas estructuras es vista por el aparato judicial.

Las discriminaciones y las violencias ejercidas en contra de las mujeres se explican desde la existencia de un sistema patriarcal, que permea la justicia y perpetúa sistemas de dominación masculina, entre ellas la familia como institución que, para las mujeres víctimas, presenta la tensión entre pertenecer a una "unidad doméstica" que las subordina y domina y, a la vez, la única posibilidad de lograr protección de la justicia.

Este artículo se preguntó por el rol que el tratamiento judicial ejerce en Colombia para superar la discriminación y dominación que genera la violencia contra las mujeres cometida por parejas y exparejas o para su reforzamiento. Los pocos casos que logran llegar a una condena judicial, como los estudiados, no tienen el potencial para transformar las estructuras de dominación y discriminación que viven las mujeres, entre otras razones, porque no contemplan en sus análisis el estudio de dichas estructuras que se dan a través del contexto en el que ocurren las violencias. Para una respuesta integral, el Estado debería aplicar en toda su intervención la consideración de que la violencia es un acto de dominio y subordinación de parte del agresor que busca anular a la víctima o desconocerla como una otra igual en derechos.

De esta manera, la finalidad última de la justicia debería consistir en restituir el lugar de sujeta de derechos de las mujeres, reconociendo su capacidad de agencia, sin que ello implique cargarlas con el peso de impulsar los procesos. Lo visto en los casos estudiados es que las condenas fueron posibles porque los agresores aceptaron cargos para beneficiarse de rebajas de pena y porque las mujeres estuvieron dispuestas a asumir su participación en los procesos, con el desgaste y riesgo que ello puede implicar. Esta conducta es excepcional y no podría constituir — como en efecto lo es- una condición para que la justicia cumpla con su labor. 
En los casos estudiados, pese a las pruebas sobre los riesgos y daños que sufrieron las mujeres, la mayoría de decisiones ignoró el potencial feminicidio que podrían desencadenar las amenazas de los agresores. Tampoco hubo reparación para las víctimas, ninguna actuación que revelara que la justicia reconocía que los hechos las habían afectado - inclusive con grados de crueldad típicos de la tortura - y que las autoridades harían algo para remediarlo. Estas omisiones del aparato de justicia, inclusive en sentencias condenatorias, reflejan el desprecio por la vida y los cuerpos de las mujeres, y lo hacen cómplice de la discriminación a la vez que perpetúan la impunidad.

La forma - aún inadecuada- como el Estado colombiano está respondiendo a la violencia contra las mujeres cometida por parejas y exparejas, protege un modelo particular de familia heterosexual y de mujer creíble, coherente y cumplidora del mandato de género, que mantiene ese lugar en la sociedad. No existen respuestas estatales contundentes para las familias y mujeres que no pertenecen a este modelo; esto tiene un efecto de jerarquización donde se crean unos sujetos merecedores y dignos de la protección estatal y otros que no lo son.

La justicia no puede solo medirse con un criterio eficientista ligado al número de condenas en contra de los agresores, sino por su potencial para transformar la vida de las mujeres y de la sociedad. El poder simbólico del derecho no debe seguir siendo un sofisma en detrimento de una vida libre de violencias y discriminación para las mujeres. 


\section{Referencias bibliográficas}

Anderson, Kristin. (2005). Theorizing Gender in Intimate Partner Violence Research. Sex roles, Query date: 2020-07-13 14:15:44. https://link.springer.com/content/pdf/10.1007/s11199005-4204-x.pdf

Barraza, Cecilia. (2018). El Género: una herramienta a favor de los derechos humanos de las mujeres y de las minorías con género no hegemónico. En Tendencias actuales de los Derechos Humanos y el Derecho Internacional Humanitario en Colombia (pp. 119- 229). Universidad Santo Tomás.

Britto, Diana. (2005). Justicia restaurativa: una mirada desde la perspectiva de género. La Manzana de la Discordia, $\quad$ 1(1), https://manzanadiscordia.univalle.edu.co/index.php/la_manzana_de_la_discordia/article/vie $\mathrm{w} / 1440 / \mathrm{pdf}$

Carroll, Llana. (2012). Leigh Goodmark. A Troubled Marriage: Domestic Violence and the Legal System. Women's Studies: An inter-disciplinary journal, 42(2), 220-222. https://doi.org/10.1080/00497878.2013.747387

Castro, Fabio y Jaramillo, Jefferson. (2018). La justicia en equidad y las violencias contra las mujeres en Colombia. Revista de Derecho (Valdivia), 31(2), 115-133. https://doi.org/10.4067/S0718-09502018000200115

Chaparro, Liliana. (2017). El principio de igualdad y no discriminación y los enfoques diferenciales como herramienta. En Jorge Carvajal, Tendencias actuales de los derechos humanos y el derecho internacional humanitario en Colombia (pp. 155-179). Colombia: ediciones USTA, Universidad Santo Tomás.

Chaparro, Liliana. (2020). La violencia contra las mujeres cometida por parte de exparejas en Colombia, ¿Una cuestión familiar? En Barraza, Cecilia. (Ed.), Debates y desafíos para los derechos humanos en Colombia (pp.177-201). Colombia: ediciones USTA, Universidad Santo Tomás.

Colombia más positiva. (2017). Riesgos de la sentencia 48047 ¿Violencia intrafamiliar o lesiones personales? http://colombiamaspositiva.com/sin-categoria/riesgos-de-la-sentencia48047-violencia-intrafamiliar-o-lesiones-personales.html 
Comisión Interamericana de Mujeres (CIM), Organización de los Estados Americanos (OEA). (1994). Convención Interamericana para Prevenir, Sancionar y Erradicar la Violencia contra la Mujer (Convención de Belém do Pará).

Congreso de Colombia (1996). Ley 294 de 1996. «Por la cual se desarrolla el artículo 42 de la Constitución Política y se dictan normas para prevenir, remediar y sancionar la violencia intrafamiliar».

Congreso de Colombia. (2000). Ley 575 de 2000. «Por medio de la cual se reforma parcialmente la Ley 294 de 1996».

Congreso de Colombia. (2008).Ley 1257 de 2008. "Por la cual se dictan normas de sensibilización, prevención y sanción de formas de violencia y discriminación contra las mujeres, se reforman los Códigos Penal, de Procedimiento Penal, la ley 294 de 1996 y se dictan otras disposiciones".

Congreso de Colombia. (2012).Ley 1542 de 2012. «Por la cual se reforma el artículo 74 de la Ley 906 de 2004, Código de Procedimiento Penal».

Congreso de Colombia. (2014). Ley 1719 de 2014. Por la cual se modifican algunos artículos de las Leyes 599 de 2000, 906 de 2004 y se adoptan medidas para garantizar el acceso a la justicia de las víctimas de violencia sexual, en especial la violencia sexual con ocasión del conflicto armado, $y$ se dictan otras disposiciones. http://www.secretariasenado.gov.co/senado/basedoc/ley_1719_2014.html

Congreso de Colombia. (2015).Ley 1761 de 2015. «Por la cual se crea el tipo penal de feminicidio como delito autónomo y se dictan otras disposiciones».

Congreso de Colombia. (2019). Ley 1959 de 2019. "Por medio de la cual se modifican y adicionan artículos de la Ley 599 de 2000 y la Ley 906 de 2004 en relación con el delito de violencia intrafamiliar».

Copelon, Rhonda. (1994). Recognizing the Egregious in the Everyday: Domestic Violence as Torture. Columbia Human Rights Law Review, 25(2), 291-368.

Corte Constitucional. (2017). Sentencia T-735/17. M.P. Antonio José Lizarazo Ocampo. Corte Constitucional. (2018). Sentencia T-462/18. M.P. Antonio José Lizarazo Ocampo. 
Corte Constitucional. (2019). Sentencia SU-479/19. M.P. Gloria Stella Ortiz Delgado.

Corte Interamericana de Derechos Humanos. (2009). Caso González y otras («Campo Algodonero») Vs.

México. https://www.corteidh.or.cr/docs/casos/articulos/seriec_205_esp.pdf

Corte Interamericana de Derechos Humanos. (2015). Caso Velásquez Paiz y Otros Vs. Guatemala, (2015).https://www.corteidh.or.cr/docs/casos/articulos/seriec_307_esp.pdf

Corte Interamericana de Derechos Humanos. (2016). Caso IV vs. Bolivia.

Corte Interamericana de Derechos Humanos. (2017). Caso Gutiérrez Hernández y Otros vs. Guatemala.

Corte Interamericana de Derechos Humanos. (2018a). Caso López Soto y Otros Vs. Venezuela. https://www.corteidh.or.cr/docs/casos/articulos/seriec_362_esp.pdf

Corte Interamericana de Derechos Humanos. (2018b). Caso Mujeres víctimas de tortura sexual en Atenco Vs. México. https://www.corteidh.or.cr/docs/casos/articulos/seriec_371_esp.pdf

Corte Suprema de Justicia. (2015). Auto AP4737.

Corte Suprema de Justicia. (2017). Sentencia SP8064.

Corte Suprema de Justicia. (2019a). Sentencia SP4135-2019 (M.P. Patricia Salazar Cuéllar 1 de octubre de 2019).

Corte Suprema de Justicia. (2019b). Sentencia SP5392-2019 (M.P. Eyder Patiño Cabrera 4 de diciembre de 2019).

Cruz, María. (2017). Acceso a la justicia de las víctimas de violencia sexual en el marco del conflicto armado colombiano [tesis de maestría, Universidad Nacional de Colombia]. Repositorio institucional Universidad Nacional de Colombia. https://repositorio.unal.edu.co/handle/unal/59230

Cubillos, Érika. (2020). Representaciones sociales sobre la violencia intrafamiliar-De pareja: ¿Violencia institucional? Una mirada desde la atención e implementación de las medidas de protección de la Ley 1257 de 2008. Estudios de caso: Comisarías de Familia de la Localidad de Suba [Pontificia Universidad Javeriana Bogotá]. https://repository.javeriana.edu.co/bitstream/handle/10554/50576/ERIKA\%20CUBILLOS\% 


\section{QUINTERO\%20-}

\%20REPRESENTACIONES\%20SOCIALES\%20SOBRE\%20LA\%20VIOLENCIA\%20INT

RAFAMILIAR-DE\%20PAREJA.pdf?sequence=1\&isAllowed=y

Echeverry, Luisa. y Bernal, Claudia. (2015). Violencia de género, algunas aproximaciones teórico-referenciales. Revista de Investigaciones UCM, 15(25), 160-169. http://dx.doi.org/10.22383/ri.v15i1.40

El Tiempo. (2019, diciembre 9). En violencia sexual e intrafamiliar, las condenas no superan el $30 \%$. https://www.eltiempo.com/justicia/investigacion/impunidad-en-casos-de-violenciasexual-e-intrafamiliar-segun-balance-de-la-fiscalia-442056

Ellsberg, Mary; Jansen, Henrica; Heise, Lori; Watts, Charlotte; y Garcia-Moreno, Claudia. (2008). Intimate Partner Violence and Women's Physical and Mental Health in the WHO Multi-country Study on Women's Health and Domestic Violence: An Observational Study. The Lancet, 371(9619), 1165-1172. https://doi.org/10.1016/S0140-6736(08)60522-X

Expósito, Francisca; Moya, Miguely Glick, Peter. (1998). Sexismo ambivalente: medición y $\begin{array}{lllll}\text { correlatos. Revista de } \quad \text { Psicología } & \text { Social, } & 13(2), & 159-169 .\end{array}$ https://doi.org/10.1174/021347498760350641

Falquet, Jules. (2017). Pax neoliberalia: Perspectivas feministas sobre (la reorganización de) la violencia contra las mujeres ( $1^{\text {a }}$ edición). Madreselva.

Forero, Jeniffer. (2018). La jurisprudencia de la corte suprema de justicia de Colombia sobre el maltrato entre ex parejas sentimentales: Análisis desde los estudios de género. Temas SocioJurídicos, 37(75), 68-91. https://doi.org/10.29375/01208578.3525

Galtung, Johan. (2003). Violencia cultural. Documento de Trabajo Fundación Gernika Gogoratuz, $n^{0}$ 14. https://www.gernikagogoratuz.org/wp-content/uploads/2019/03/doc-14violencia-cultural.pdf

Garzón, Rubén. (2006). Modelo de la escalada de la violencia en contexto conyugal. Aporte desde el trabajo social forense. La Manzana de la Discordia, 1(2), 39-52. https://manzanadiscordia.univalle.edu.co/index.php/la_manzana_de_la_discordia/article/vie $\mathrm{w} / 1422 / \mathrm{pdf}$

Gómez, Dianay Estrada, Lina. (2017). Dificultades en las competencias jurisdiccionales en 
materia de violencia intrafamiliar de las comisarías de familia. Revista CES Derecho, 8, 139155.

Goodmark, Leigh. (2019). The Unintended Consequences of Domestic Violence Criminalization: En Janet Halley, Prabha Kotiswaran, Rachel Rebouché, y Hila Shamir (Eds.), Governance Feminism: An Introduction (pp. 124-156). University of Minnesota Press; JSTOR. www.jstor.org/stable/10.5749/j.ctvdjrpfs.9

Gorjón, María. (2010). La respuesta penal frente al género. Una revisión crítica de la violencia habitual y de género [Tesis doctoral, Universidad de Salamanca]. Repositorio Institucional Universidad de Salamanca. https://gredos.usal.es/handle/10366/83229

Goyeneche, Fredi; Pardo, Jerryy Marmol, Oswaldo. (2018). Marco interpretativo de la dinámica social de la violencia intrafamiliar en Cartagena 2008-2017. Saber, Ciencia y Libertad, 13(1), 180-197.

Grupo de Monitoreo para la Implementación de la CEDAW en Colombia. (2019). Mujeres y paz, en búsqueda de plenos derechos. Informe sombra del grupo de monitoreo para la implementación de la CEDAW en Colombia. Colombia: La Iglesia Sueca, ONU Mujeres.

Guzmán, Liliana. (2019).Lineamientos para la protección de mujeres en riesgo de violencia mortal por parte de parejas o exparejas. [Tesis de Maestría, Universidad Santo Tomás. Repositorio institucional Universidad Santo Tomás. https://repository.usta.edu.co/handle/11634/20361

Indaburu, Julianay Sarmiento, Juliana. (2020).Justicia restaurativa y violencia intrafamiliar: un acercamiento desde las Casas de Justicia [Tesis de pregrado, Pontificia Universidad Javeriana Bogotá]. Repositorio institucional Pontificia Universidad Javeriana Bogotá. https://repository.javeriana.edu.co/bitstream/handle/10554/50974/20200625\%20Tesis\%20Fi nal.\%20Juliana\%20Sarmiento\%20y\%20Juliana\%20Indaburu\%20\%282\%29converted.pdf?sequence $=1 \&$ is Allowed $=\mathrm{y}$

Instituto Nacional de Medicina Legal y Ciencias Forenses. (2017). Boletín Epidemiológico "Valoración del riesgo de violencia mortal contra mujeres por parte de su pareja o expareja: Prevención secundaria”. https://www.medicinalegal.gov.co/documents/20143/57992/Valoración+del+riesgo+de+viol 
encia+mortal+contra+mujeres+por+parte+de+su+pareja+o+expareja+Prevención+secundari a.pdf

Instituto Nacional de Medicina Legal y Ciencias Forenses. (2019). Forensis 2018. Datos para la vida.

Isaza, Maritza. (2006). Prácticas de las mujeres que viven violencia conyugal frente a la atención en la fiscalía. La Manzana de la Discordia, 1(2), 31-38. https://manzanadiscordia.univalle.edu.co/index.php/la_manzana_de_la_discordia/article/vie w/1421/pdf_1

Jelin, Elizabeth. (2010). Pan y afectos. La transformación de las familias. Fondo de Cultura Económica.

Kelly, Liz. (2000, noviembre). Violencia doméstica[sesión de conferencia] Foro Mundial de Mujeres Contra la violencia. Organizado por Centro Reina Sofía para el Estudio de la Violencia. Valencia, España. https://www.google.com/search?q=Kelly\%2C+L.+(2000)+La+violencia+dom\%C3\%A9stica $. \& o q=$ Kelly\%2C+L.+(2000)+La+violencia+dom\%C3\%A9stica.\&aqs=chrome..69i57.2017j0 j8\&sourceid $=$ chrome $\&$ ie $=U T F-8$

Kim, Mimi. (2020). Anti-Carceral Feminism: The Contradictions of Progress and the Possibilities of Counter-Hegemonic Struggle. Affilia - Journal of Women and Social Work, 35(3), 309326. Scopus. https://doi.org/10.1177/0886109919878276

Lagarde, Marcela. (2003). Los cautiverios de las mujeres: Madresposas, monjas, putas, presas y locas. Universidad Nacional Autónoma de México.

Lemaitre, Julieta. (2008). Violencia. En La mirada de los jueces Género en la jurisprudencia latinoamericana. Tomo 1 (pp. 549-630). Siglo del Hombre Editores, American University Washington College of Law, Center for Reproductive Rights.

Londoño, Beatriz. (Ed.). (2013). El papel de los jueces contra la violencia de pareja en Colombia, 2005-2009. Bogotá: Universidad del Rosario, Facultad de Jurisprudencia.

Londoño, Beatriz; Estefan, Soraya; Sierra, Jimenay Coral, Ana. (2013). Violencia contra la pareja en Colombia y América Latina: anotaciones conceptuales y jurídicas. En BeatrizLondoño (Ed.), El papel de los jueces contra la violencia de pareja en Colombia, 2005-2009(pp.1-39). 
Universidad del Rosario. Facultad de Jurisprudencia.

Lux, Martha. y Pérez, María. (2020). Los estudios de historia y género en América Latina. Historia Crítica, 77, 3-33.

MacKinnon, Catharine. (1995). Hacia una teoría feminista del Estado. Cátedra.

Martínez, Agustín. (2016). La violencia. Conceptualización y elementos para su estudio. Política y cultura, (46), 7-31.

Martínez, Julia. (2011, diciembre). Violencia simbólica contra mujeres. Revista Pueblos.http://www.revistapueblos.org/old/spip.php?article2290

Martínez, Karol. y Rodríguez, Camilo. (2020). La violencia intrafamiliar y de género. Una visión del caso colombiano. Principa Iuris, 16(34), 98-127.

Núñez, Lucía. (2019). Reflexiones sobre los límites y utilidades del sistema penal para enfrentar la violencia de género. Cuadernos de investigación, 2, 193-211.

Oficina del Alto Comisionado de las Naciones Unidas para los Derechos Humanos (OACDH). (1979). Convención sobre la Eliminación de todas las Formas de Discriminación contra la Mujer $(C E D A W)$.

Oficina del Alto Comisionado de las Naciones Unidas para los Derechos Humanos (OACDH). (1993). Declaración sobre la eliminación de la violencia contra la mujer. https://www.ohchr.org/sp/professionalinterest/pages/violenceagainstwomen.aspx

Osorio, Beatriz. y Pérez, Estefanía. (2018). Variación jurisprudencial en la interpretación del delito de violencia intrafamiliar en Colombia [tesis de especialización, Universidad Libre seccional Cúcuta]. Repositorio institucional Universidad Libre. http://hdl.handle.net/10901/11889

Poggi, Francesca. (2019). Sobre el concepto de violencia de género y su relevancia para el derecho. DOXA, Cuadernos de Filosofía del Derecho, 42, 285-307. https://doi.org/10.14198/DOXA2019.42.12

Procuraduría General de la Nación, y Representantes de las organizaciones de mujeres del Comité de seguimiento a la Ley 1257 de 2008. (2017). Políticas actuales sobre violencias hacia la mujer ponen en riesgo la efectividad y cumplimiento de la ley 1257. 
https://www.sismamujer.org/wp-content/uploads/2018/06/PRONUNCIAMIENTO-NOVIOLENCIA-CONTRA-LAS-MUJERES-FIRMADO-1.pdf

Ramos-Aranda, Lina; Jiménez-Torres, Libiay Thola-Ospitia, Yudy. (2018). Impacto jurídico de las violencias contra mujeres víctimas de violencia de pareja o expareja. Colombia Forense, 5(1), 19-33. https://doi.org/10.16925/cf.v5i1.2302

Risman, Barbara. (1998). Gender Vertigo. American Families in Transition. Yale University Press.

Sarmiento, Diana. y Pinzón, Brinzeth. (2019). La necesidad de la conciliación en el delito querellable de violencia intrafamiliar en la mujer a partir de la ley 1542 de 2012 en el municipio de Piedecuesta, Santander [tesis, Universidad de Santander]. Repositorio institucional Universidad de Santander . https://repositorio.udes.edu.co/handle/001/4463

Secretaría de la mujer y equidad de género. Gobernación del Atlántico. (2017). "Violencia contra las exparejas: Un vacío jurídico”, tema del $8^{\circ}$ Diálogo de Paz de la Gobernación.

Segato, Rita. (2003). Las estructuras elementales de la violencia (Edición: 1st.). Universidad Nacional de Quilmes.

Tepichin, Ana. (2019). Violencia por razón de género durante la postseparación: Dificultades de las mujeres para la subsistencia. La Manzana de la Discordia, 4(2), 56-81.

Viveros, Mara. (2016). Sex/Gender. A brief History of the Concept. En The Oxford Handbook of Feminist Theory (pp. 852-873).Oxford University Press

Walker, Leonore. (2012). El síndrome de la mujer maltratada (J. C. Plaza, Trad.).Desclée de Brouwer Editores.

Wittig, Monique. (2010). El pensamiento heterosexual y otros ensayos (J. Sáez y P. Vidarte, Trads.). Egales.

\section{Sentencias estudiadas}

Caso 1. Sentencia del Juzgado 20 Penal Municipal de conocimiento, Bogotá, Rad. 110016000 016201605637 00, sentencia del 9 de enero 2020. 
Caso 2. Sentencia del Juzgado 12 Penal Municipal de conocimiento, Bogotá, Rad. 110016099 0692016 09839, sentencia del 20 junio 2018.

Caso 3. Sentencia del Juzgado 12 Penal Municipal de conocimiento, Bogotá, Rad. 110016000 1062016 03185, sentencia del 19 de diciembre de 2018.

Caso 4. Sentencia del Juzgado 33 Penal Municipal de conocimiento, Bogotá, Rad. 110016000 017201612975 00, sentencia del 11 de septiembre 2019.

Caso 5. Sentencia del Juzgado 20 Penal Municipal de conocimiento, Bogotá, Rad. 110016099 069201613600 00, sentencia del 6 de noviembre de 2019.

Caso 6. Sentencia del Juzgado 52 Penal del Circuito de conocimiento, Bogotá, Rad. 110016101 9112017 01906, sentencia del 15 de agosto de 2019

Caso 7. Sentencia del Juzgado 20 Penal Municipal de conocimiento, Bogotá, Rad. 1100160 000132017 07306, sentencia del 6 de junio de 2018.

Caso 8. Sentencia del Juzgado 15 Penal Municipal de conocimiento, Bogotá, Rad. 11001 600010620160158400, audiencia de legalización de principio de oportunidad en modalidad renuncia del 4 de marzo de 2020.

Caso 9. Sentencia del Juzgado 12 Penal Municipal de conocimiento, Bogotá, Rad. 11001 6000017201805194 , sentencia del 8 de abril de 2019.

Caso 10. Sentencia del Juzgado 15 Penal Municipal de conocimiento, Bogotá, Rad. 110016000015201902367 , sentencia del 11 de febrero de 2020.

Caso 11. Sentencia del Juzgado 12 Penal Municipal de conocimiento, Bogotá, Rad. 110016099069201908967 , sentencia del 11 de diciembre de 2019.

Caso 12. Sentencia del Juzgado 22 Penal Municipal de conocimiento, Bogotá, Rad. 11001600013201909067 , sentencia del 9 de enero de 2020. 